\title{
From Drawings by the Blind to Music by the Deaf*
}

\section{Jay Rahn}

The starting-point for this report consists of a series of studies by John Kennedy, who is currently Chair of the Department of Life Sciences, Scarborough College, University of Toronto. In his 1993 book Drawing and the Blind, Kennedy summarized his earliest studies of visualspatial perception and production among persons who were totally blind since birth (https://tspace.library.utoronto.ca/handle/1807/1021 : to facilitate continuous reading, I cite online resources wherever feasible in what follows).

In Drawing and the Blind, Kennedy dispelled the myth that pictorial perspective is inaccessible to blind persons. In particular, persons who are blind draw pictures that convey all three dimensions, including depth or distance from ego, i.e., the observer or draughtsperson. Among other findings, Kennedy also showed that blind persons contrive pictorial conventions or metaphors for motion and speed (e.g., persons walking or running, and wheels spinning or rolling).

The blind persons with whom Kennedy has worked have employed a very simple and relatively inexpensive technology. This technology, namely, raised-line drawing, involves impressing a semi-rigid surface with a stylus (http://www.nationalbraille.org/GRAPHICS.html*: note that existing drawings can be automatically transformed into raised-line drawings through such technology as Pictures In a Flash, so that raised-line drawings can be shared worldwide instantaneously, e.g., via pdf files: http://www.visiontech.svrc.vic.edu.au/piaf.htm*).

Blind persons draw pictures in this medium with no training -- and conversely interpret or 'read' such images with considerable fluency -- as do sighted persons after a certain amount of practice. Moreover, several blind persons have produced a considerable output of such raised-line drawings, as Kennedy's eloquent life-and-works account of Gaia exemplifies (Perception, 32 (2003): 321-40).

Most arresting in Kennedy's work is that it raises the prospect of blind persons drawing for one another. That is, there might be a 'visual art' not only for the blind -- as in the talking pictures promoted by various art galleries -- but also by the blind. Could there, then, be music not only for the deaf but also by the deaf?

An initial lead is provided in the second last chapter of Drawing and the Blind (https://tspace.library.utoronto.ca/retrieve/2239/Drawing and the Blind_Chap8.pdf, pp. 27279). There, Kennedy reports experiments in 'auditory' perception he carried out with persons

* Author's note, January 21, 2011. Since the original presentation in 2004, several of the urls to which the text was linked have become obsolete. These are indicated by means of an asterisk (*). Otherwise, the present text is as presented in 2004. 
who were hard of hearing or deaf. In the experiment, sounds were played through a large, hometheatre-size speaker, the vibrations of these sounds being conveyed to a deaf or hard of hearing person's forearms, any airborne sound from the speakers being masked by headphones. Although I believe Kennedy's main reported finding can be explained in terms of the instrumentation he used and the design of the experiment itself -- the subjects' responses were of three kinds, only one of which, the octave, was not exemplified in preliminary, 'training' session, and the specific octave used in the experiment comprised $60 \mathrm{~Hz}$ and $120 \mathrm{~Hz}$, which might have been even more distinctive if the speaker transmitted 60-cycle hum -- his results indicated clearly that deaf and hard of hearing persons distinguish among different kinds of sounds in a way that far exceeds chance.

Most important, the actual perception involved in such stimulation is not auditory in the usual sense. Instead, sonic distinctions are a product of tactile perception, as is the way in which blind persons -- or sighted persons for that matter -- read raised-line drawings. Plausibly, music for and/or by the deaf might be mediated not by auditory perception, but by tactile perception: more specifically, vibrotactile perception, that is, the perception of periodic sound waves through the skin. Already there are 'pictures to touch.' Might there also be 'pieces to feel'?

As it turns out, preliminary steps toward such a music of the deaf, or simply 'deaf music,' have been achieved, albeit without such an end in view. In order to account for why the goal of a truly deaf music has not been intensively sought, I outline fairly recent developments in technology that have had an important effect on many who are deaf or hard of hearing, namely, cochlear implants, vibrotactile devices, and the internet. Thereupon, I outline ways in which deaf music might be realized - that is, realized by persons who are deaf.

\section{INTRODUCTION}

Despite their widely acknowledged usefulness to persons who have been deaf and hard of hearing, the 'reception' of cochlear implants, vibrotactile devices and the internet raises questions for disability studies.

(One cannot help but notice that Enforcing Normalcy by Lennard Davis (1995), seemingly an authoritative publication in the field of disability studies, does not once mention any of these technologies (nor music in general), even though the main illustrations of his book are based on developments among persons who are deaf or hard of hearing generally, and specifically within the Deaf community. To be sure, use of the internet by the Deaf, the deaf, and the hard of hearing seems not to have become widespread when Lennard wrote; however, cochlear implants and vibrotactile devices had already become important).

In the present account, answers to questions for disability studies are sought with regard to the following:

- a demographic profile of persons who are deaf and hard of hearing

- limitations of the three technologies 
- organizations and sectors involved in developing and implementing the technologies

- widespread values concerning hearing

In outline, the present report is organized around the following observations and questions concerning cochlear implants and vibrotactile devices:

\section{Cochlear Implants}

Since their introduction about 25 years ago, cochlear implants have been widely thought to be a panacea for the severely and profoundly deaf. To those who have had no hearing or virtually no hearing, cochlear implants have provided real-time access to speech and other kinds of sound.

- Nonetheless, relatively few persons who are severely or profoundly deaf have been implanted during the past 20 years or so.

- Why?

For about 15 years, many of those who have been implanted have complained about the way in which cochlear implants transmit music and other kinds of sound. Despite advances in cochlear implant technology and a variety of post-operative programs, such complaints persist among a large number of those who have been implanted.

- Why? And how might improvements take place?

\section{Vibrotactile Devices}

Developed about the same time as cochlear implants, vibrotactile devices have been used in combination with hearing aids and oralist/auralist methods in order to help the hard of hearing develop and refine their speaking skills, relative to the 'normal' population.

- All the same, 'deaf speech' has persisted among many who are hard of hearing and their complaints concerning music have paralleled disappointments of cochlear implantees.

- Why? And how might improvements take place?

\section{DEMOGRAPHIC PROFILE OF PERSONS WHO ARE DEAF AND HARD OF HEARING}

A great variety of elicitation techniques and definitions are used to determine how many people are deaf or hard of hearing. As the Gallaudet Research Institute has emphasized, it is difficult to assess how many persons in particular parts of society are deaf or hard of hearing (http://gri.gallaudet.edu/Demographics/deaf-US.php*). Nonetheless, certain figures seem reliable if one triangulates -- or even 'polygonates' -- the many sources of data.

Depending on how one interprets the available data, persons who are deaf and hard of hearing comprise anywhere from 8 to 28 million Americans, i.e., ca. 3\% to $10 \%$ of the population. Of these, about 400,000 to 700,000 are severely or profoundly deaf. That is, for about 2 to 4 
persons per 1000 in the population as a whole, the threshold of hearing is $70 \mathrm{~dB}$ or greater. Although such equations can mislead, one can estimate that for such persons much of an orchestral performance of Mozart's Overture to the Magic Flute at a concert would be barely or entirely inaudible and much conversation would not be comprehended (http://hyperphysics.phyastr.gsu.edu/hbase/sound/dba2.html\#c1 ).

According to FDA regulations and various insurance programs, such persons generally qualify for cochlear implants. However, only about 50,000 persons who are severely or profoundly deaf have been implanted: i.e., fewer than about $13 \%$ of those who qualify have been implanted. Why such a small percentage?

Various organizations have stressed that in all parts of the population there are persons who are deaf and hard of hearing. Nevertheless, within this general observation one can discern disproportionate demographic tendencies. According to the Gallaudet Center for Assessment and Demographic Studies, about $50 \%$ of persons who are deaf and hard of hearing are over 65 . Across all ages, the deaf and hard of hearing tend to be poor, male, and of European descent. Moreover, deaf and hard of hearing persons tend to live in rural regions and have fewer years of formal education than the population as a whole. As well, such persons tend to have lower rates of employment, especially between the ages of 45 and 65 .

Comparing such figures with the initial cost of a cochlear implant yields an important reason for the relatively low rate of implantation: namely, poverty. On one hand, for every deaf and hard of hearing person whose annual family income is at least $\$ 50,000$, there are two whose annual family income is less than $\$ 10,000$. On the other hand, the initial cost of a cochlear implant is ca. $\$ 40,000$ to $\$ 50,000$ : Less than a year's income for the families of the relatively few in the top bracket, but at least 4 years of an entire family's income for the relatively many at the low end (http:/gri.gallaudet.edu/Demographics/factsheet.html\#Q1*).

Although I am not aware of immediately relevant data having been compiled, it seems reasonable to conjecture that those who live in rural regions are less readily served by the urban and university hospitals that tend to be centers for cochlear implantation. Such persons also are less likely to be employed in unionized workplaces that provide disability benefits and disability accommodation, or in workplaces of sufficient size to generate an official infrastructure for monitoring and enforcing health and safety standards. In the latter regard, it is significant that about a third of the deaf and hard of hearing persons interviewed about 10 years ago for the National Center for Health Statistics reported that the cause of their disability was 'noise' (ibid., Table 12).

Because deaf and hard of hearing persons tend to be of European background, advocacy for the deaf and hard of hearing might seem to run counter to the agendas of those advancing the causes of persons whose identity is African American or Hispanic. However, according to the National Association for the Deaf, those who actually are implanted are disproportionately European in origin. Persons of European background who qualify for a cochlear implant are almost 4 times 
more likely to be implanted than qualified Hispanics, and almost 5 times more likely than qualified African Americans

(http://www.nad.org/infocenter/infotogo/dcc/CIjan01/CIandeducation.html*).

Similarly, whereas males are more likely to be deaf or hard of hearing, this tendency is not as marked or uniform across other demographic variables as are the ethnic disparities just outlined. To be sure, from birth through adolescence, about 25\% more males are deaf or hard of hearing. However, from age 65 onwards, about 4 times as many females become deaf or hard of hearing. This is a far greater disparity than can be explained by relative longevity, for as the US Census reports, females above the age of 65 have outnumbered males only by about $50 \%$ (http://www.census.gov/prod/1/pop/p23-190/p23-190.pdf).

Further, whereas about twice as many males are deaf or hard of hearing between the ages of 19 and 65, such a disparity might be accounted for by the relative underemployment of females in rural areas - especially insofar as about a third of those interviewed for NCHS cited as the cause of their disability 'noise,'including 'loud brief noise'. Department of Labor figures appear to support this explanation, for they show clearly that males have continued to far outnumber females in such high-decibel work as farming, fishing, forestry, construction, extraction, installation, maintenance, repair, production, transportation, and material moving (ftp://ftp.bls.gov/pub/special.requests/lf/aat39.txt ). Of particular significance, many of these highdecibel jobs are located in 'non-metro' areas, i.e., in the relatively sparsely populated countryside. In short, whereas younger persons who are deaf or hard of hearing tend to be males -- markedly so during the period of 'normal' adult employment -- women almost 'catch up' during their years of 'normal retirement.'

\section{LIMITATIONS OF COCHLEAR IMPLANT TECHNOLOGY}

Soon after cochlear implant surgery began on a relatively large scale, complaints arose among implantees. To be sure, an ability to hear and understand speech returned to those who had lost all or most of this ability. However, what many implantees reported when hearing music via a cochlear implant was quite distressing.

Complaints about the bionically transduced sounds of cochlear implants resulted in increased research and the commercial release of new, improved models. As Fan-Gang Zeng, who heads up the University of California at Irvine's Hearing and Speech lab, has noted, during the 1990s the number of refereed medical research articles concerning cochlear implants surpassed those that dealt with hearing aids and currently comprises at least 200 per year (http://www.ucihs.uci.edu/hesp/publications/Trend_Zeng.pdf, Fig. 2, p. T4).

Three American corporations now manufacture cochlear implants and support related research and development projects. Among the changes that have been introduced are technologies that help to isolate naturally occurring speech sounds from the 'booming buzzing confusion' of ambient noise that surrounds them. All the same, despite continuing technological advances, such 
companies' finances have been somewhat volatile (e.g., http://yahoo.reuters.com/financeQuoteCompanyNewsArticle.jhtml?duid=mtfh67734_2004-0927 06-57-35_syd293244_newsml*).

With regard to the sounds of music as compared with speech, researchers have made available sound files that provide laypersons with an idea of what the sounds transmitted by a cochlear implant actually 'sound like' to an implantee. An especially compelling and concise demonstration of the strengths and weaknesses of current cochlear implant technology is available at Robert V. Shannon's website for the House Ear Institute's Department of Auditory Implants and Perception (DAIP: http://www.hei.org/research/depts/aip/ringdemo.mp3*).

The DAIP sound file just cited illustrates various stages of cochlear implant technology. In their original, 1970s form, cochlear implants processed sounds through a single electronic channel. The beginning of the file illustrates the effect of such single-channel processing. Subsequently, additional channels were added, all the way up to the 8 illustrated in the second last passage of the sound file. As one can hear, speech aspects of the song are more readily heard than musical aspects. Further, in comparison with the tune and its arrangement, the lyrics are deciphered in earlier versions, i.e., those that involve fewer channels.

It would be reckless to infer that all cochlear implantees hear the song in precisely one of the ways illustrated by this sound file. Nevertheless, the amount and kind of sonic information conveyed by its last and second last versions provide a fairly good estimate of the outer boundaries of implant hearing. Though such comparisons can be misleading, the increase in detail from 1 to 8 channels can be considered relative to the reception of persons with 'normal hearing,' for whom more than 20,000 sterocilia are intact.

(For a more complete impression, http://www.hei.org/research/depts/aip/audiodemos.htm* provides links to other simulations by Shannon's lab, including the opening of a well-known instrumental work by Gershwin and a passage of speech; separate simulations for a single passage of speech and a similarly well-known passage of instrumental music by Tchaikovsky can be accessed at Zeng's website: http://www.ucihs.uci.edu/hesp/procSim/simulations.htm).

A reason why musical aspects of the simulations sound distorted to abled, 'normal hearing' listeners and a reason why musical aspects of the implanted sounds that correspond to the simulation sound distorted to cochlear implantees - especially to those who have become severely or profoundly deaf later in life -- are also a reason why speech aspects of the song fare so much better. Specifically, an initial aim of cochlear implant technology was to make speech accessible to the deaf and hard of hearing.

To realize this goal, researchers focused on conveying important aspects of speech to the auditory nerve: in particular, the spectra of vowels and consonants in naturally occurring languages. To put these spectra into perspective, one can note that the frequencies transmitted by the telephone lines used by those with 'normal hearing' range from about $300 \mathrm{~Hz}$ to $3000 \mathrm{~Hz}$ 
(i.e., from approximately E-flat at the bottom of the treble-clef staff to about g" two octaves above the treble clef staff: $h$ ttp://www.indiana.edu/ iuhear/s478/SPACOUST.htm*). Moreover, speech sounds mainly require sonic information within bands of frequency (i.e., 'formants') that are relatively wide and relatively few

(http://cslu.cse.ogi.edu/tutordemos/SpectrogramReading/ipa/formants.html*)

By contrast, musical pitch structures generally involve similarities and differences among much narrower frequency bands. For example, instead of three formants for vowels, musical tones usually feature many harmonics that often vary in amplitude throughout a single tone. Additionally, fundamental frequencies for musical tones generally extend far below $300 \mathrm{~Hz}$ and aesthetically relevant aspects of musical timbre extend far above $3000 \mathrm{~Hz}$. Accordingly, even the 8 frequency bands employed for the second last version of the song considered above -- though quite ample for understanding speech -- provide a very sparse basis for comprehending, appreciating or enjoying music. In sum, that speech was of higher priority than music has resulted in complaints of implantees who recall having heard music in quite a different form before becoming severely or profoundly deaf.

Little wonder then that Kate Gfeller of the University Iowa found in a 1998 survey of persons who had been implanted that whereas $60 \%$ enjoyed and participated in music on their own, $25 \%$ participated in music only at the behest of others, $8 \%$ gave no reaction to music, and $8 \%$ hated music (http://www.listen-up.org/ci/music-ci.htm). Asked to rate on a scale of 1 to 10, from least to most enjoyable, $52 \%$ of persons with implants in a follow-up study by the Cochlear Corporation last March gave music a rating in the upper end of the scale; $43 \%$, a rating in the lower half. About a third said they could usually identify a familiar song without being told the title; about a third said they could usually recognize a familiar melody with no lyrics; and about a third said they could usually identify a familiar musical instrument by its sound alone (http://www.hearingloss.org/ciai/ja2004.html*).

These subjective responses have been consistent with the results of experimental testing. Using the Primary Measures of Music Audiation test (PMMA; http://www.giamusic.com/scstore/Pmusicaudiation.html*) and a Musical Instrument Quality Rating, Gfeller found in 1991 that persons with cochlear implants scored worse than those with 'normal hearing' in every musical task except those involving simple rhythms. Very inaccurate in same-different comparisons when melodic patterns included small pitch changes, such implanted persons were also less accurate in recognizing familiar instruments by sound alone and in responding to more complex rhythms (Gfeller et al. Journal of Speech and Hearing Research (1991) 34/4:916). Other studies have confirmed Gfeller's findings in further detail, observing, for example, that pitch distinctions between consecutive tones required frequency differences of 4 semitones or more (Fujita et al. Ability of Nucleus Cochlear Implantees to Recognize Music. Annals of Otology, Rhinology and Laryngology 108/7 (1999):634-40: http://www.annals.com/1999/Jul99 abstracts.htm*; see also http://www.phys.unsw.edu.au/ jw/reprints/FearnThesis.pdf ). 


\section{RESPONSES BY RESEARCHERS}

Medical researchers have continued their attempts to improve pitch and timbral aspects of implants and have even provided non-psychoacoustical conjectures of great promise to those who work with implanted persons in an audiological or therapeutic setting. For instance, Zeng found that the otherwise anomalous difficulty implantees encounter in dealing with relatively complex rhythms corresponds to deficits in short-term, working memory (op. cit., T22). From such research one might begin to address difficulties that would otherwise have seemed intractable.

Similarly, working within the often demonized 'medical model,' Dewey Lawson and co-workers at the Research Triangle Institute's Center for Auditory Prosthesis research have developed proprietary interactive MIDI software that persons with implants could, in principle, use in order to produce sounds they themselves like (http://www.rti.org/reports/capr/N01-DC-82105QPR08.pdf, p. 20). Along much the same lines, Zeng's website has provided free online applets that, in principle, anyone can use for self-assessment of various aspects of their own hearing, i.e., without recourse to a professional audiologist (http://www.ucihs.uci.edu/hesp/webtest/webtest.htm: *On-Line Hearing Tests no longer archived).

As a further example, such researchers as Emmanuel Bigand of the Centre National de la Recherche Scientifique (CNRS) in Dijon, France, have been developing software whose aim can be understood as developing 'therapy readiness' (http://www.u-

bourgogne.fr/LEAD/people/bigand/gira.htm). Bigand's work focuses on implicit learning, familiarization, and self-directed enjoyment through games -- rather than on explicit learning, which, with its convergent, normative, 'normalizing' aims, tasks, and tests, has dominated the most successful forms of speech therapy. As such, Bigand's research seems most appropriate to the arguably aesthetic realm of music, which, as Crafts, Cavicchi, and Keil have shown in My Music (1993), persons in the developed world understand and 'appreciate' in highly idiosyncratic ways.

\section{RESPONSES BY HELPING SEMI-PROFESSIONS}

To the extent that such research directions result in resources that are available for free and readily accessible to, and controlled by, implantees they will mark a significant development in the history of disabilities. By contrast, the efforts of various helpers of the deaf and hard of hearing are less easy to assess with regard to music. Consider, for instance, the following advice that Kay, of listen-up-org, has promulgated among implant users on the basis of Gfeller's research: 'The more listening an implant user does, the better music sounds. Go from simple music to more complicated pieces, such as progressing from nursery rhymes to duets to quartets to orchestras' (http://www.listen-up.org/ci/music-ci.htm ).

This account matches the advice of Cochlear ${ }^{\mathrm{TM}}$ : http://www.cochlear.com/533.asp*), a cochlear implant corporation who emphasizes to potential buyers that 'Cochlear has many Nucleus recipients who enjoy and appreciate music. Music is comprised of many complex sounds and may take practice. There are a few factors that influence your progress, for instance: prior 
experience with music, motivation and practice' (http:/www.cochlear.com/943.asp*). Such counsel seems to have become widely dispersed among audiologists. Reminiscent of the horse's advice in Orwell's Animal Farm, such directions amount to little more than 'just try harder,' and ignore well established intricacies of auditory scene analysis.

Nonetheless, like the Cochlear Corporation, the University of California at San Francisco's Douglas Grant Cochlear Implant Center exclaims that 'many [cochlear implant users] are able to communicate by regular telephone or enjoy music!'

(http://www.ucsf.edu/implant/commonmyths.html). And suggestions that can be traced to Gfeller's early research seem to have attained the status of lore among audiologists. Indeed, Beukes, whose work has been sponsored by Advanced Bionics, replicates much of this and yet pleads to implantees in this Spring's issue of the Newsletter for the National Cochlear Implant Users Association in the UK, 'If you have ideas that worked really well for you or a specific type of music that you find easy to listen to, or if you know someone who has, then please let us know.' (http://www.nciua.demon.co.uk/music1.html*)

Other forms of music therapy for the deaf and hard of hearing seem similarly well- meaning and ill-informed or uninformative. For example, Hear \& Listen! Talk \& Sing! and Songs for Listening! Songs for Life! adapt materials and methods of Orff pedagogy to therapeutic ends -- lesson plans corresponding to 'individually-structured therapy sessions... specifically designed ... by a select group of Certified Auditory-Verbal Therapists from around the world.' One might find troubling not only the price of the latter 'outstanding publication' ( $\$ 98.95$ for 238 pp.) but also the close links among the principal author and the publisher (namely, the Alexander Graham Bell Association for the Deaf and Hard of Hearing), the principal author's employment by the Learning to Listen Foundation (http://www.learningtolisten.org/publications.html*), the latter foundation's 'outstanding scholarly journal' (Listen), which the principal author edits and which is published by the Auditory-Verbal Foundation (http://auditory-verbal.org/AVIPub.asp*), whose corporate members include Cochlear Americas, Advanced Bionics, and The Listen Foundation (http://auditory-verbal.org/AVIAbout.asp*) and whose other publications include the principal author's 50 Frequently Asked Questions About Auditory-Verbal Therapy, which the American Academy of Audiology's review has awarded 3 out of 5 'ears,' criticizing the volume for its 'broad generalizations about other approaches (e.g., auditory training and speech-language pathology: http://www.audiology.org/professional/books/r0008.php*).'

None of this overlap in personnel and interests and none of the evident competition between sectors of the helping semi-professions would be quite so troubling if the effectiveness of theories, methods, and materials promoted in this way were actually tested, using standard, 'medical model' protocols like arm's-length, double- or triple-blind studies with control groups, including placebo controls. That such studies seem not to have been carried out leads one to believe not only that music therapy does not count for much in a world of sound where speech is significantly connected to economic productivity and domestic workload, but also that such forms of therapy are effectively, to adapt a phrase of Tom Lehrer, 'therapies for the rich ... and their family members.' Not that such forms of therapy might not perform a diversionary or recreational role, but they seem not to offer the kinds of basic choices requested by persons who 
are themselves deaf and hard of hearing.

\section{TESTIMONY OF PERSONS WHO DEAF AND HARD OF HEARING}

For this kind of testimony, one can readily access such websites as Jamie Berke's deafness/hard of hearing bulletin board (http://forums.about.com/ab-deafness/messages ). There one will find that choice is a major theme-disputes about freedom to choose concern to a great extent relationships between children and parents. The range of opinions, practices, and individual situations persons who are deaf or hard of hearing report is much broader than one will encounter in the statements of those who are merely 'stakeholders.'

In such colloquy, persons who are deaf or hard of hearing identify desirable roles for music that are quite varied: something in the background that should not interfere with speech, something to be heard live or on recording, something to be danced or skated to, something to be heard again after a long time since hearing began to decline, something to understand the lyrics of, something to write lyrics for, something to sing along with, something to be played on piano for pleasure, something to be played in an ensemble, something to hear one's spouse singing, ....

In contrast to normative assumptions about musical performance, the following statement by a forum participant might draw many music instructors up short: 'Looking back, for the life of me I don't understand how I did learn to play [the piano] with no hearing. How much easier it is to play now when I can depend on hearing, as before the implant it was all sight.' For this person, there has been music, including music performance, without any hearing, a corollary of which is that hearing is not a necessary condition for music making. Reminiscent of my own response to the sounds of an MRI machine is the advice of another person with an implant: 'There is one drawback but to me it's no problem, and that's tinnitus (head noises). Since I have had them from the time I went very deaf, I know how to handle it. One simple way is to turn it into music. Never sit there and moan and groan, as it seems to know you hate it and thrives to make your head spin. Go with the flow and it will settle down.'

In sum, whereas the 1988 NIH non-Federal, non-advocacy consensus statement on cochlear implants emphasized that 'Few medical interventions yield outcomes as varied as those for cochlear implantation (http://consensus.nih.gov/cons/068/068 statement.htm\#2_*), the testimony of persons with implants seems as variegated as the outcomes. Nonetheless, the range of what such persons consider music serves as a corrective and a challenge to silently shared assumptions of those with 'normal hearing.'

\section{NORMATIVE CONCEPTS OF MUSIC AND 'MUSIC'}

Arguably informed by Platonic Ideas of Beauty and Perfection, understandings of music--or 'Music'-- that have been shared by professional musicians and laypersons locate fine-grain details of pitch and timbre at the center of interest, rhythm at the periphery - generally the reverse of what is readily shared with those who are deaf or hard of hearing. On one hand is the 'flawless' 
performance of 'Music,' not to mention the transcendent or insightful performance of 'the Music' (apparently widespread in advanced performance instruction; see, for example, Henry Kingsbury's 1988 Music, Talent, and Performance). On the other hand is talk of 'degraded' sound among those who undertake research concerning cochlear implants. However, one cannot simply blame the history of European ideas for the value judgments that result.

For instance, Aristotle's notion of perfection comprised completeness, and at least one important European writer on music understood this to mean sufficiency. Marchetto of Padua's distinction between perfect and pluperfect melodic ranges hinges on the idea that a melody need only instantiate its modal octave in order to be considered perfect in ascent or descent. Tones above or below the modal octave are not excessive; rather they are 'more than sufficient.' In such a sense, then, sounds that do not comprise all the details available to those with 'normal hearing' need not be understood as conveying a deficient rendering of a piece. Instead, they might be understood as conveying a sufficient rendering of a version of the piece (just as a piano-vocal score can provide a sufficient version of an opera).

\section{VIBROTACTILE DEVICES}

Originally patented in 1975, the technology of vibrotactile devices depends on the finding that sound waves transmitted to the surface of the body's largest organ, namely, the skin, result in predictable sensations. (http://patft.uspto.gov/netahtml/srchnum.htm* , 3,875,932). These sensations are intersubjective to a much greater extent than responses to sound waves transmitted via cochlear implants. So reliable and immediate are the 'feelings' that result from vibrotactile stimulation that they provide a basis for wearable devices used in situations of danger or urgency.

Transmitted to persons who are deaf/hard of hearing and/or vision impaired are short, simple, coded, vibrotactile messages that replace or complement, for example, smoke and fire alarms, which otherwise would depend on hearing or seeing (http://www.rnid.org.uk/html/information/technology/smoke alarms.htm* ${ }^{*}$. Similarly, wearable vibrotactile devices, which usually consist of small speakers, have been developed to transmit orders to soldiers in combat, where hearing and vision are temporarily impaired and to convey information about a patient's vital signs to an anesthesiologist during surgery. (http://18.62.2.144/WiegandT/proposals/stim.htm*)

Many persons who are deaf or hard of hearing wear vibrotactile devices to complement hearing aids, lip reading, or sign language during conversation. (see, e.g., http://www.tactaid.com/miamtacstud.html*) Because vibrotactile devices transform changes in the amplitudes of sound waves at particular frequencies, redundant information that vibrotactile stimulation adds to the auditory and visual information of speech can help persons who are hard of hearing or deaf to discern which syllables are relatively stressed and to distinguish among the formant structures of various phonemes. 


\section{CONSTRAINTS ON VIBROTACTILE TECHNOLOGY}

A difficulty in achieving the kinds of redundancy sought this way consists in the fact that stress or accent in such intonation languages as English depends less on hearing greater loudness than on hearing various patterns of pitch: generally, to use musical terms, a syllable marked by a glissando, a relatively high pitch, or a change in pitch is relatively accented (Alan Cruttenden.

Intonation, 2 ed., 1997). Because vibrotactile responses vary in perceived area, depth, and location on the skin depending on both amplitude and frequency, changes in what would be heard as pitch and loudness are readily confused along a variety of cognitive dimensions. Nonetheless, there have been attempts to contrive technologies that convert the sounds of music in the usual sense into vibrotactile stimulation.

\section{MUSICAL APPLICATIONS OF VIBROTACTILE TECHNOLOGY}

The most ambitious of these attempts appears to be the Skinscape/Cutaneous Grooves project developed by Eric Gunther a few years ago at MIT's Media Lab Gunther contrived a wearable suit comprising 12 tiny speakers that vibrate at various points on the skin: shoulders, forearms, wrists, thighs, shins, and ankles:

http://ic.media.mit.edu/Publications/Conferences/CutaneousGroove/PDF/CutaneousGrooves.pdf. These speakers convey sound waves that stimulate Pacinian corpuscles. Located just below the skin's surface, Pacinian fibres are most responsive to frequencies near $250 \mathrm{~Hz}$ (approximately middle $\mathrm{C}$ ). These speakers are complemented by a relatively large speaker that is worn as a backpack and is especially effective at conveying sound vibrations to which non-Pacinian receptors respond, their most responsive frequencies being around $50 \mathrm{~Hz}$ (approximately $\mathrm{G}$, an octave below the bass-clef staff: http://www.sonoma.edu/users/h/hanesda/B497/bear12.htm).

Through such clothing Gunther has conveyed pieces that can be heard and/or felt. In some pieces, the felt sensations are immediate transformations of sounds that are simultaneously 'heard' (i.e., in the usual sense). In others, sounds felt provide a vibrotactile counterpoint to sounds heard. In still others, felt sounds are conveyed, whereas the corresponding heard sounds are masked by means of headphones.

Even more promising for felt music is another technology developed at MIT's Media Lab. Angela Chang has contrived a sleeve that fits over a cell phone so that two people (or, in principle, more than two in a conference-call setting) can transmit simultaneously to one another not only heard sounds but also sounds that are felt at the most sensitive locations on a person's skin, namely, the inside surface of the fingers, especially the tips of the index finger and thumb. (http://www.medialabeurope.org/palpable/comtouch_dis.PDF*)

Chang's work opens up the prospect of felt music being improvised by a fairly large ensemble, with or without the corresponding sounds of heard music. That such a novel form of music might involve improvisation is indicated by Chang's finding that when placed in the hands of subjects in 
an experimental setting, conversationalists spontaneously invented, without apparent awareness, coded vibrotactile conventions to supplement what they said and heard.

Gunther's more recent musical experiments include art gallery installations involving displays to be viewed and felt and what could be termed vibrotactile 'sittables,' not to be confused with such putatively therapeutic devices as the various 'vibroacoustic' (VA) chairs and other devices marketed by the Somatron Corporation. Feasible, then, are forms of felt music not only for, but also by, the deaf and hard of hearing.

\section{A MUSICAL FUTURE FOR VIBROTACTILE DEVICES?}

Why forms of felt music have not become widespread can be traced to several factors. Instrumentation for felt music has been developed only in the last few years and is likely to remain relatively costly and restricted in circulation until competitive marketing takes hold. To be sure, 'handfelt' ensemble music might well emerge within the larger community that uses cell phones, just as in Sweden persons who sign have enthusiastically seized on the potential of cell phones with visual display in order to converse almost anywhere, anytime. More important, as with cochlear implants, prospects for speech have been of much higher priority than prospects for music.

Even within disability frameworks that acknowledge as a central value well-being or quality of life, participation in music has ranked low. Further, on one hand, existing, well established kinds of heard music that correspond closely to feasible forms of felt music abound: for example, traditional drumming ensembles, minimalist percussion pieces, and techno-pop idioms. On the other hand, such forms have not been widespread throughout Euro-American society, nor have they been among the first sorts of expression that large numbers of westerners identify most readily as 'music,' let alone 'Music' or 'the Music.'

All the same, at the Rocket club in London, recent special evenings of music with signed lyrics and sounds that are sufficiently intense, especially in the bass register, to be felt as well as heard have been highly popular among dancers, including not only persons who are deaf and hard of hearing but also those with 'normal hearing.' (http://news.bbc.co.uk/1/hi/magazine/3621529.stm) In this regard, it is noteworthy that the felt sounds have been sufficient for dancing but have not conveyed enough detail for persons who are deaf or hard of hearing to distinguish between popular music idioms - as would developments along the lines of Gunther's work.

In a world large enough to include Chicago's Gaetano 'Tom' Adamo, who bills himself as the world's only deaf signing Elvis impersonator (http://members.aol.com/DeafElvis/*), and Wilsonville Oregon's Andrew Hordichok, who teaches middle-school music (http://www.oregonlive.com/news/oregonian/index.ssf?/base/front page/1095076574105490.xml* ) a future for music both for and by the deaf and hard of hearing seems assured, despite systemic impediments. 